\title{
The impact of overactive bladder on health related quality of life.
}

1. MBBS, FCPS

Assistant Professor Obstetrics \&

Gynecology

PAQSJ Gambat Institute of Medical

Sciences

Gambat, Khairpur Sindh.

2. MBBS, FCPS

Senior Registrar

PAQSJ Gambat Institute of Medical

Sciences

Gambat, Khairpur Mirs Sindh.

3. MBBS, FCPS

Instructor Obstetrics \& Gynecology PAQSJ Gambat Institute of Medical

Sciences

Gambat, Khairpur Mirs Sindh.

4. MBBS, FCPS

Senior Registrar

Health Department Sindh Govt

5. MBBS, FCPS

Consultant Gynaecologist

Civil Hospital Karachi.

6. MBBS, FCPS

Senior Registrar

PAQSJ Gambat Institute of Medical

Sciences

Gambat, Khairpur Mirs Sindh.

Correspondence Address:

Dr. Hafiza Khatoon

Department of Obstetrics \&

Gynecology

PAQSJ Gambat Institute of Medical

Sciences

Gambat, Khairpur Sindh.

drhafizakhatoonpk@gmail.com

Article received on:

15/01/2020

Accepted for publication:

20/09/2020
Hafiza Khatoon', Safia ${ }^{2}$, Ambreen $\mathrm{Naz}^{3}$, Nousheen Mushtaq ${ }^{4}$, Tahira Awan ${ }^{5}$, Rukhsana Ahmed ${ }^{6}$

ABSTRACT... Objective: To determine the impact of overactive bladder on health related quality of life (HRQOL). Study Design: Cross Sectional study. Setting: Department of Obstetrics and Gynaecology, Gambat Institute of Medical Sciences Gambat, Khairpur Sindh. Period: 1st November 2018 to 30th June 2019. Material \& Methods: One Hundred forty nine women included who fulfilled inclusion criteria after taking inform consent. The questionnaire consisting of domain of general health perception, urinary incontinence, role limitation on physical, social \& personal relationship, emotion with score was analyzed. Each question was carry 1 point as score .Score was analyzed further on percentage basis. Those who gain $>33 \%$ were be labeled as impact of overactive bladder -ve patients. Finally data was analyzed on SPSS version 21. Results: The present study consisted of 145 subjects presented to the Department of Psychiatry, Services Hospital Lahore (both in and Out-patients). Over reactive bladder were matched on age, sex and socio-economic status \& educational status. The age range of the total sample was $23-60$ years. Mean age was $42.53+11.69$. The duration of symptoms range of the total sample was $09-20$ years. Mean duration was $16.7+5.6$. The prevalence of over reactive bladder $(\mathrm{OAB})$ syndrome were found $21 \%$, respectively. The age were divided in to four classification age groups $17(11.7 \%)$ under the age of $<30$ years, $31(21.4 \%)$ under the age of $31-40$ years, $85(58.6 \%)$ found under the age of $(58.6 \%) \& 41-50$ Years of age $85(58.6 \%)$ Women constitute the largest age groups. Out of 145 Women $68(46.9 \%)$ were Illiterate, $48(33.1 \%)$ were literate up to intermediate, $29(20 \%)$, took graduation education. The distribution of income classes of women $61(42.06 \%)$ belong to low class, $65(44.84 \%)$ belong to middle class and only $19(13.10 \%)$ belong to upper class. The parity distributions were revealed that most of the $78(53.7 \%)$ women had multiparty. Stratification of confounding variable for effect modifier Age \& parity were found to be significantly associated with over reactive bladder syndrome. Again Stratification of confounding variable for effect modifier socio economic status \& education status are not found significantly associated with over reactive bladder syndrome \& $P$-Value were not found significantly associated with $O A B P>0.05$. Conclusion: We concluded incidence of overactive bladder in the female is almost similar and associated with increasing your age. Patients of $O A B$ are under-diagnosed and under-treated. This patient can benefit from standard tests.

Key words: $\quad$ Epidemiology, Overactive Bladder, Quality of Life.

Article Citation: Khatoon H, Safia, Naz A, Mushtaq N, Awan T, Ahmed R. The impact of overactive bladder on health related quality of life. Professional Med $\mathrm{J}$ 2021; 28(4):470-474. https://doi.org/10.29309/TPMJ/2021.28.04.6050

\section{INTRODUCTION}

Current international continence society ICS over active bladder is defined as urinary urgency with or without urge incontinence usually with frequency and nocturia if there is no infection or proven pathology; its diagnosis is based on symptoms alone rather than aerodynamic findings. ${ }^{1}$ It can be classified as over active bladder (OAB) wet with incontinence or $(\mathrm{OAB})$ dry without incontinence. Urinary incontinence (U.I) is most common chronic problem affecting the women, although it is not a life threating condition, but it can severely affect quality of life of women. ${ }^{2}$

World health organization (WHO) defined as not merely the absence of disease but complete physical mental and social well-being. Quality of life has been used to mean a combination of patient assessed measure of health, including physical function, role function, social function, emotional 
or mental state, burden of symptoms and sense of well-being. ${ }^{3}$ Urinary incontinence is known to have profound impact on quality of life (Q.O.L) affecting all domains including physical, social, psychological, occupational activities of daily and sexual function. ${ }^{4}$ Approximately 200 million people worldwide suffer urinary incontinence and less than $20 \%$ received treatment. The $\mathrm{WHO}$ Conservative estimates are that worldwide direct and indirect cost of urinary incontinence exceeds \$ 60 million annually. ${ }^{5}$ According to female sexual function index questioners (FSFI) four domain desire arousal organism and satisfaction were significantly decreased in over active bladder group. ${ }^{6}$

In us study found 900 women treated for over active bladder $23 \%$ were not able to go short outing, $12 \%$ stayed at home more than often then they would have perfect for sexual life, nearly half women experienced sexual dysfunction. ${ }^{7}$ Increased enjoyment don't feeling to urinate and anxiety. These issues strained relationships with their spouse. OAB has also has impact on mental health, increased depression and anxiety, worse quality of slip. In Korean study $37 \%$ participant with $\mathrm{OAB}$ reported moderate to severe difficulties to their daily life this made house work more difficult. ${ }^{8}$ European study by Milson \& coworkers $65 \%$ men, $67 \%$ women with OAB reported that their symptom. Liberman \& associate recently conducted a large US community based survey on effect of OAB on HRQL, reported women urge incontinence $26 \%$ greater risk of fall, $34 \%$ risk fracture. ${ }^{9}$

\section{MATERIAL \& METHODS}

This observational study was conducted at Department of Obstetrics and Gynaecology, after the ethical approval of Gambat Institute of Medical Sciences Gambat, Khairpur Sindh, from 1st November 2018 to 30th June 2019. NonProbability consecutive sampling technique was used. Data were collected through outdoor patients with detailed history and thoroughly examination. Patients with $\mathrm{OAB}$ who fulfill the criteria were married women of age between 1860 years, Nulliparous, Multiparous and Grand Multiparous women. While exclusion criteria were diabetes, Abdomina / Pelvic "Mass, pregnancy, current \& recurrent Urinary tract Infections, pelvic organ descent and any neurological disorder that effect bladder normal function such as multiple sclerosis, spinal cord injuries. The questionnaire consisting of domain of general health perception, urinary incontinence, role limitation on physical, social \& personal relationship, emotion with score was analyzed. Each question was carry 1 point as score .Score was analyzed further on percentage basis. Those who gain $>33 \%$ were be labeled as impact of OAB -ve patients."

Data were entered and analyzed in SPSS version 20 , through filled proforma and were analyzed statistically for mean, frequency and percentage were calculated for all quantitative variable. Mean+SD were calculated for age \& duration of symptoms. Frequency \& percentages were calculated for Impact of OAB on HRQOL, Parity, and socioeconomic status. To see the effect on $\mathrm{OAB}$, Post stratification chi-square test were applied $<0.05$ were taken as significant.

\section{RESULTS}

Over reactive bladder were matched on age, sex and socio-economic status \& educational status. The age range of the total sample was 23-60 years. Mean age was $42.53+11.69$ years. The prevalence of over reactive bladder (OAB) syndrome $21 \%$ (Figure-1). The age were divided in to four classification age groups $17(11.7 \%)$ under the age of $<30$ years, $31(21.4 \%)$ under the age of $31-40$ years, $85(58.6 \%)$ found under the age of (58.6\%) \& 41-50 Years of age 85(58.6\%) Women constitute the largest age groups (Table-I). Out of 145 Women 68(46.9\%) were Illiterate, 48(33.1\%) were literate up to intermediate, $29(20 \%)$, took graduation education (Table-I). The distribution of monthly income of women were $61(42.06 \%)$ belong to low class, $65(44.84 \%)$ belong to middle class and only $19(13.10 \%)$ belong to upper class. The parity distribution were revealed that most of the $78(53.7 \%)$ women had multiparity. Stratification of confounding variable for effect modifier Age were found to be significantly associated with over reactive bladder syndrome (Table-II). Stratification of confounding variable for effect modifier socio economic status \& 
education status are not significantly associated with over reactive bladder syndrome (Table-II).

\begin{tabular}{|c|c|c|}
\hline Variable & Frequency & Percentages \\
\hline \multicolumn{3}{|l|}{ Age Groups } \\
\hline - $\quad<30$ Years & 17 & $11.7 \%$ \\
\hline - $\quad 31-40$ Years & 31 & $21.4 \%$ \\
\hline - $\quad 41-50$ Years & 85 & $58.6 \%$ \\
\hline - $\quad>50$ Years & 12 & $8.2 \%$ \\
\hline \multicolumn{3}{|l|}{ Education Status } \\
\hline - Illiterate & 68 & $46.9 \%$ \\
\hline $\begin{array}{l}\text { - Literate up to } \\
\text { intermediate }\end{array}$ & 48 & $33.1 \%$ \\
\hline - Graduate & 29 & $20 \%$ \\
\hline \multicolumn{3}{|c|}{ Social Economic Status } \\
\hline - $\quad$ Lower Class & 61 & 42.06 \\
\hline - $\quad$ Middle Class & 65 & 44.84 \\
\hline - Upper Class & 19 & $13.10 \%$ \\
\hline
\end{tabular}

Table-I. Demographic variable $(\mathrm{N}=145)$

\begin{tabular}{|c|c|c|}
\hline \multirow{2}{*}{ Variable } & \multicolumn{2}{|c|}{ Overactive Bladder } \\
\hline & Positive (\%) & Negative (\%) \\
\hline \multicolumn{3}{|l|}{ Parity Distribution } \\
\hline - Nulli Parity & $18(12.4 \%)$ & $32(22.1 \%)$ \\
\hline - $\quad$ Multi Parity & $12(8.3 \%)$ & $66(45.5 \%)$ \\
\hline - $\quad$ Grand Multiparty & $1(0.7 \%)$ & $16(11 \%)$ \\
\hline \multicolumn{3}{|l|}{ Age Distribution } \\
\hline - $\quad$ Age $<30$ Years & $03(2.1 \%)$ & $14(9.7 \%)$ \\
\hline - $\quad$ Age 31-40 Years & $6(4.1 \%)$ & $25(17.2 \%)$ \\
\hline - Age 41-50 Years & $15(10.3 \%)$ & $70(48.3 \%)$ \\
\hline - $\quad$ Age $>50$ Years & $7(4.8 \%)$ & $05(3.4 \%)$ \\
\hline \multicolumn{3}{|l|}{ Education Distribution } \\
\hline - Illiterate & $15(2.1 \%)$ & $53(9.7 \%)$ \\
\hline $\begin{array}{l}\text { - } \quad \text { Literate up to } \\
\text { intermediate }\end{array}$ & $12(4.1 \%)$ & $36(17.2 \%)$ \\
\hline - $\quad$ Graduate & $04(10.3 \%)$ & $25(48.3 \%)$ \\
\hline \multicolumn{3}{|l|}{ Social Status } \\
\hline Lower class & $09(6.2 \%)$ & $52(35.9 \%)$ \\
\hline - $\quad$ Middle Class & $17(11.7 \%)$ & $48(33.1 \%)$ \\
\hline - Upper Class & $05(3.4 \%)$ & $14(9.7 \%)$ \\
\hline \multicolumn{3}{|c|}{$\begin{array}{l}\text { Table-II. Comparison of overactive bladder with } \\
\text { multiple variable of patients }(\mathrm{N}=145)\end{array}$} \\
\hline
\end{tabular}

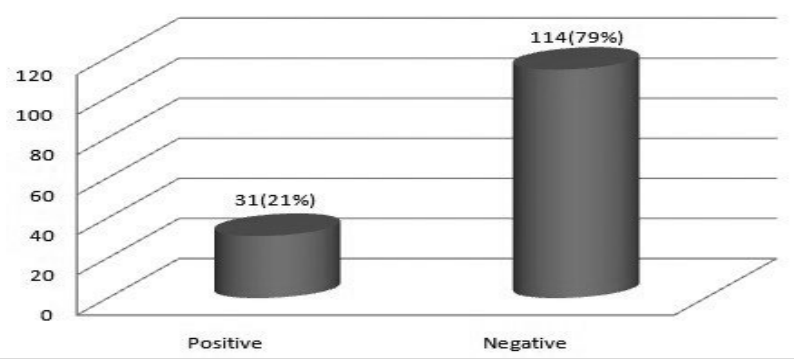

Figure-1. Impact of overactive bladder on health related quality of life (HRQOL)

\section{DISCUSSION}

The study revealed that out of the 145 patients which we measured the prevalence of over reactive bladder syndrome (OAB) status in a welldefined population of women which was based on quality of life questionnaire. We found that over reactive bladder is found only in $31(21 \%)$ out of 145 total number of patients is relatively common in women.

Overactive bladder $(\mathrm{OAB})$ is a frequent disabling situation that impacts health-related best of lifestyles. ${ }^{10}$ Estimates of the occurrence and have an effect of $O A B$ on quality of life vary widely, in phase due to variation in the evaluation of symptoms, the populations surveyed, the techniques used to collect data, and the standards used to outline OAB.

Overactive bladder is a subset of storage lower urinary tract symptoms (LUTS) defined as 'urgency, with or without urge incontinence, usually with frequency and nocturia'. The European Prospective Investigation into Cancer and Nutrition (EPIC) study was reported previously estimated the overall incidence of OAB in Europe and Canada to be $12.8 \%$ amongst women and $10.8 \%$ amongst men, whereas the overall incidence of any LUTS used to be estimated to be $62.5 \%$ in men and $66.6 \%$ in women. ${ }^{11}$ Studies show that people with OAB often delay seeking help and wait an average of three years before consulting a physician. ${ }^{12}$ Therefore; it is challenging to estimate the occurrence and, greater generally, the societal influence of $O A B$ based totally on medical encounter data. To date, two major epidemiological research have appeared at the occurrence of OAB. However, neither of them included symptom bother in their analysis, and consequently can also overestimate the incidence of the situation.

We understand that the incidence of $O A B$ syndrome will increase with age, there is a lack of information regarding the impact of $O A B$ syndrome on sexual lifestyles yet. The prevalence of $\mathrm{OAB}$ is probable to be over $16 \%$ in United States and $6 \%$ to $35 \%$ in Europe. ${ }^{13,14}$ Korean continence society conducted study on OAB and 
reported the prevalence of OAB syndrome over age of forty was found in $30.5 \%$ cases. ${ }^{14}$

Prevalence the overactive bladder syndrome increased with age and have a major effect on quality of life ranging $12-17 \%$ of the population. ${ }^{15,16}$ In our study observed mean age was $42.53+$ 11.69 years (Age range was 23 to 60 years). however the study conducted by Saleem $A$ et al in 2010 in national journal and reported mean ages of women were $46.53 \pm 11.94$ years (range 21-74 years) with overactive bladder syndrome. ${ }^{17}$ Our results demonstrated age groups of women between 41-50 years of age of women patients that is more aged population \& carries significance association after review of literature. Overactive bladder syndrome can have a significant effect on quality of life and prevalence increases with their age. However the Study of Milsom I reported prevalence of overactive bladder varied between 7.7 and $31.3 \% .^{18}$

\section{CONCLUSION}

We concluded incidence of overactive bladder in the female is almost similar and associated with increasing your age. Patients of OAB are underdiagnosed and under-treated. This patient can benefit from standard tests.

Copyright@ 20 Sep, 2020.

\section{REFERENCES}

1. Johnston KM, Walker DR, Lakzadeh P. Characterizing the health-related quality of life burden of overactive bladder using disease-specific patient-reported outcome measures: A systematic literature review. Advances in therapy. 2019 Mar 1; 36(3):548-62.

2. Khullar V, Chapple C, Gabriel Z, Dooley JA. The effects of antimuscarinics on health-related quality of life in overactive bladder: A systematic review and metaanalysis. Urology. 2006 Aug 1; 68(2):38-48.

3. Liu R, Ding K, Chunlu BO, Dai B, Zhai J, Yuanyuan LI, Zhang Q, Cuiping XU. Effect of nursing intervention on women with overactive bladder: A systematic review. Chinese J Practical Nursing. 2018 Jan 1; 34(12):917-20.

4. Jayadevappa R, Cook R, Chhatre S. Minimal important difference to infer changes in health-related quality of life-a systematic review. J Clinical Epidemiology. 2017 Sep 1; 89:188-98.
5. Mazur-Bialy Al, Kołomańska-Bogucka D, Nowakowski C, Tim S. Urinary incontinence in women: Modern methods of physiotherapy as a support for surgical treatment or independent therapy. J Clinical Med. 2020 Apr; 9(4):1211-8.

6. McNabney SM, Wiese GN, Rowland DL. From table to bedroom: Nutritional status, dietary interventions, and women's sexual function. Current Sexual Health Reports. 2019 Dec 1; 11(4):251-64.

7. Patel AS, O'leary ML, Stein RJ, Leng WW, Chancellor $M B$, Patel SG, Borello-France D. The relationship between overactive bladder and sexual activity in women. Int Braz J Urol. 2006 Feb; 32(1):77-87.

8. Lai HH, Rawal A, Shen B, Vetter J. The relationship between anxiety and overactive bladder or urinary incontinence symptoms in the clinical population. Urology. 2016 Dec 1; 98:50-7.

9. Nitti VW. Clinical impact of overactive bladder. Reviews in Urology. 2002; 4(Suppl 4):S2-6.

10. Srikrishna S, Cardozo L. The impact of overactive bladder on female sexual function. European Urological Review. 2012; 7(1):61-3.

11. Irwin DE, Milsom I, Hunskaar S, Reilly K, Kopp Z, Herschorn S, et al. Population-based survey of urinary incontinence, overactive bladder, and other lower urinary tract symptoms in five countries: Results of the EPIC study. Eur Urol 2006; 50:1306-14.

12. Eduard $\mathrm{C}$, Kelleher $\mathrm{C}$. The cost of not treating overactive bladder. (2007): 70-2.

13. Safarinejad MR. Prevalence of the overactive bladder among Iranian women based on the International Continence Society definition: A population-based study. Int Urol Nephrol. 2009; 41(1):35-45.

14. Walters MD, Taylor S, Schoenfeld LS. Psychosexual study of women with detrusor instability. Obstet Gynecol1990; 75:22-6.

15. Oh SJ, Ku JH, Choo MS, Yun JM, Kim DY, Park WH. Health-related quality of life and sexual function in women with stress urinary incontinence and overactive bladder. Int J Urol. 2008; 15(1):62-7.

16. Griebling TL. Overactive bladder in elderly men: Epidemiology, evaluation, clinical effects, and management. Curr Urol Rep. 2013 Oct; 14(5):418-25.

17. Saleem A. In women with urinary incontinence how necessary is cystometry? J Pak Med Assoc. 2010; 60(5):356-9. 
18. Milsom I. Lower urinary tract symptoms in women.

Curr Opin Urol 2009; 19: 337-41.

\begin{tabular}{|c|c|c|c|}
\hline \multicolumn{4}{|c|}{ AUTHORSHIP AND CONTRIBUTION DECLARATION } \\
\hline Sr. \# & Author(s) Full Name & Contribution to the paper & Author(s) Signature \\
\hline 1 & Hafiza Khatoon & $\begin{array}{l}\text { Conception and design, } \\
\text { Statistical expertise. }\end{array}$ & \\
\hline 2 & Safia & $\begin{array}{l}\text { Critical revision of the article for } \\
\text { important intellectual content. }\end{array}$ & \\
\hline 3 & Ambreen Naz & Data collection. & \\
\hline 4 & Nousheen Mushtaq & $\begin{array}{l}\text { Data colelction Critical revision } \\
\text { Drafting of the article. }\end{array}$ & \\
\hline 5 & Tahira Awan & Data collection. & \\
\hline 6 & Rukhsana Ahmed & Data collection. & \\
\hline
\end{tabular}

